to shake off a disk of material that could subsequently form the Moon.

Science http://dx.doi.

org/10.1126/science.1226073; http://dx.doi.org/10.1126/

science.1225542 (2012)

\section{BIOMATERIALS}

\section{Super-reflective fish skin}

Three species of silvery fish seem to have found a way around a law of physics that governs the reflection of light.

The skin of the Atlantic herring (Clupea harengus), European sardine (Sardina pilchardus; pictured) and sprat (Spratus spratus) is made up of alternating layers of cytoplasm and highly reflective crystals of guanine - a molecule that is also found in DNA and RNA. Nicholas Roberts and his colleagues at the University of Bristol, UK, report that the fishes' skin can reflect light without polarizing it, even when the light hits the reflectors at angles that would normally result in fully polarized reflections. The skin contains a mixture of two types of guanine crystal with different optical properties when the two are present in a specific ratio, this mixture prevents polarization and maintains high reflectivity.

These reflectors help the fish to camouflage themselves by matching the light environment of the open ocean, say the authors. Moreover, the principles at work in these fish could have applications in optical devices such as light-emitting diodes. Nature Photon. http://dx.doi. org/10.1038/nphoton.2012.260 (2012)

For a longer story on this research, see go.nature.com/ndcqjt \section{on the steady decay rate of
carbon-14 in samples, and
archaeologists calibrate this
carbon clock by comparing
the known ages of tree rings
with their carbon ages. But the
tree-ring carbon record goes}

\section{CANCER}

\section{Targeting a vicious cycle}

Cancer cells proliferate by sending the cell cycle into overdrive, but early attempts to target the cell cycle with drugs were marred by problems with toxicity. Now two groups show that shutting down cell-cycle proteins called D-type cyclins without affecting normal tissue.

Piotr Sicinski and his colleagues at the Dana-Farber Cancer Institute in Boston, Massachusetts, engineered mice in which the production of cyclin D1 can be switched on and off. Loss of the protein had no apparent effect on healthy adult mice, but halted the growth of mammary tumours in mice that were also genetically predisposed to developing breast cancer.

Sicinski's team, and Iannis Aifantis at the New York University School of Medicine and his colleagues, showed independently that loss of cyclin D3 either triggered the death of tumour cells, or prevented their growth, in mouse models and human cell lines of an aggressive form of leukaemia. Inhibiting downstream proteins called cyclin-D associated kinases also killed tumour cells.

Cancer Cell 22, 438-451; 452-465 (2012)

\section{A more accurate carbon clock}

Determining the age of fossils and other ancient objects could become more accurate, thanks to measurements of radioactive carbon-14 from a lake in Japan.

Radiocarbon dating is based seems to stop tumour growth

COMMUNITY CHOICE

The most viewed papers in science

\title{
Sudden rupture in deadly earthquake
}

\section{HIGHLY READ \\ on www.agu.org $150 \mathrm{ct}-210 \mathrm{ct}$}

A brutal secondary rupture may have been responsible for much of the devastation caused by the Wenchuan earthquake, which killed more than 69,000 people in

Sichuan province, China, on 12 May 2008.

A team led by Guohong Zhang of the China Earthquake Administration in Beijing used ground-acceleration data from a national network of earthquake-monitoring stations to reconstruct the spread of the 7.9-magnitude quake. Records from 26 local stations indicate that the main slip area - a high-friction patch of fault located 25 to 50 kilometres from the epicentre - resisted the seismic stress building up around it for about 30 seconds. The slip area then failed catastrophically in a sudden 12.5-metre jolt.

Researchers have long hypothesized that an initial quake can trigger secondary ruptures. The study shows that this is a realistic scenario, the team concludes.

Geophys. Res. Lett. http://dx.doi.org/10.1029/2012GL052516 (2012)

back only about 14,000 years, and less reliable marine records have been used to fill the gap. Christopher Ramsey at the University of Oxford, UK, and his colleagues extracted roughly 70-metre-long core samples from the bed of Lake Suigetsu. By counting the number of distinct sediment layers in the core - two layers have formed every summer and winter over the past 52,000 years - the team was able to compare the ages of the layers with their carbon-dated ages.

The more accurate carbon-14 record could help archaeologists to fine-tune the dates of key events, such as the coexistence of humans and Neanderthals.

Science 338, 370-374 (2012)

For a longer story on this research, see go.nature.com/pbv6ey

\section{PHOTONICS}

\section{White LEDs without glare}

A new luminescent material reduces the glare of white light-emitting diodes (LEDs) and could make them more

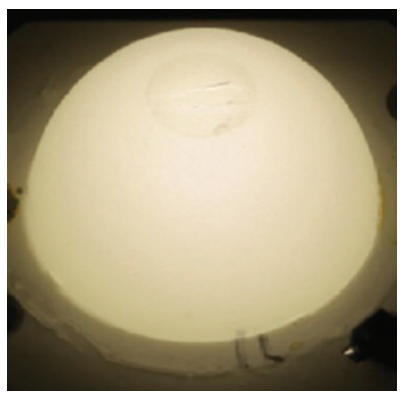

practical for home lighting.

A team led by Hisayoshi Daicho of Koito Manufacturing in Shizuoka, Japan, designed the material, which consists of chlorosilicates that have been implanted with europium ions. The phosphor absorbs violet light and re-emits it in a yellow shade. The researchers combined this phosphor with a blue one and then added a violet LED to create a system that emits white light with a uniform hue (pictured) and no glare.

Nature Commun. http://dx.doi. org/10.1038/ncomms2138 (2012)

\section{$\rightarrow$ NATURE.COM}

For the latest research published by Naturevisit:

www.nature.com/latestresearch 